\title{
CORRECTION
}

\section{Correction: Role of zinc in neonatal growth and brain growth: review and scoping review}

Luc P. Brion, Roy Heyne and Cheryl S. Lair

Pediatric Research (2021) 89:1871; https://doi.org/10.1038/s41390-021-01425-6

Correction to: Pediatric Research https://doi.org/10.1038/s41390020-01181-z, published online 03 October 2020

Narrative Review section, 8th paragraph: $\mathrm{Zn}$ accretion in the fetus: The first sentence should read:
Most of $\mathrm{Zn}$ accretion in utero occurs during the second and third trimesters of pregnancy; therefore, preterm infants, especially ELGANs, are at risk for Zn deficiency. 